\title{
The COVID-19 pandemic is exacerbating the care crisis in Latin America and the Caribbean ${ }^{1}$
}

The coronavirus disease 2019 (COVID-19) pandemic has brought to light, in an unprecedented way, the importance of care for the sustainability of life and the low visibility of this sector in the economies of the region, where it is still considered an externality and not a fundamental component of development. The ongoing health crisis highlights the unfair social organization of care work in Latin America and the Caribbean. There is an urgent need to consider responses to care needs from a gender perspective, since, as the Economic Commission for Latin America and the Caribbean (ECLAC) has repeatedly demonstrated, it is women who, whether paid or unpaid, bear the greatest caregiving burden.

\section{Women's excessive caregiving burden}

1. Among other measures, the World Health Organization (WHO) has recommended social distancing to reduce the speed at which the virus spreads. This crucial measure has led to the closure of educational establishments and greatly expanded telework.

2. As at 30 March 2020 , according to data from the United Nations Educational, Scientific and Cultural Organization (UNESCO), schools had been closed at the national level in 37 countries and territories in the region (UNESCO, 2020). This means that at least 113 million children and adolescents are at home to prevent the spread of the virus. The closures of these educational establishments mean that this population group requires 24-hour care, undoubtedly putting a strain on families' time, particularly that of women, who spend three times as long as men on unpaid domestic and care work each day in the region.

3. Prior to the COVID-19 health crisis, in the countries of the region for which data are available, women spent between 22 and 42 hours a week on domestic and care work.

\section{Gender inequalities are even greater in lower-income households}

4. Gender inequalities are sharper in lower-income households, where demands for care are greater (as there tend to be more dependants). In addition, other inequalities are exacerbated, as it is very difficult to maintain social distancing when infected people live in homes that do not have sufficient physical space to provide health care and protect high-risk groups from exposure to the virus.
Summary

- Women's excessive caregiving burden

- Gender inequalities are even greater in lower-income households

- The importance of health care

- The fragility of paid domestic work

- The importance of gendersensitive policies

Everyone relies on care provided by other people during most of their life. Care work encompasses the production of goods and rendering of services that are essential for life, such as preparing food, providing physical and emotional support, transmitting knowledge and values, and tending on people to ensure their well-being. Care work highlights the interdependence between people who receive care and those who provide it (whether paid or unpaid), and that care should be understood as a right (to provide care, to be cared for, to not provide care and to care for oneself).

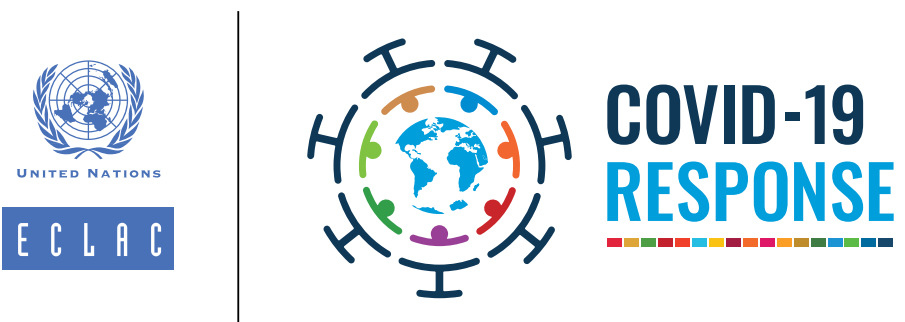


A paradigm shift is needed for care to be considered a universal right that requires the creation and linking together of benefits to be progressively guaranteed within countries, with serious implications for the institutions responsible for care policy, the definition of the role of the State and the consolidation of social

co-responsibility. To this end, comprehensive and integrated measures must be adopted on behalf of those who require care and those who provide it

Furthermore, in the domestic sphere, there must be a move towards greater co-responsibility between men and women. This will require the formulation of cultural, time-use and economic policies that support a change in behaviour and a redefinition of roles
5. Unequal access to basic services remains a regional problem. For example, 13.5\% of households in the region did not have access to improved water sources in 2018, and the situation was worse in rural areas, where the proportion was 25.4\%. ${ }^{2}$ Furthermore, women living in households with limited access to drinking water spend between 5 and 12 more hours per week on unpaid domestic and care work than women living in households without such privations. ${ }^{3}$

6. Likewise, students with fewer resources cannot continue their education by digital means, since not all homes or educational establishments have the tools, skills and technologies needed to operate in this manner.

7. According to ECLAC data, in Latin America and the Caribbean in 2017 only $52.2 \%$ of households had access to the Internet and $44.7 \%$ had a computer. In addition, a number of skills and abilities are required to implement distance learning, among education sector workers, who are mostly women (69.8\% of workers in this sector), ${ }^{4}$ among students, and among those who supervise and support educational activities at home.

8. The crisis has highlighted the gap in the skills needed to use the information and communications technology (ICT) required for distance learning, as well as in the skills of education professionals, parents and students. This is an ongoing challenge for the region, especially for women in the lower income strata.

\section{The importance of health care}

9. As early as 2016, ECLAC had drawn attention to the complexity of the organization of health care and how families take charge of family members' health care. This involves, among other tasks, purchasing medicines, engaging services and providing direct care for sick people.

10. There are several different reasons for this situation, including the cost of health services, which impedes access to health care, especially for people from low-income sectors. To quantify this unpaid health care, in Mexico, for example, it was estimated that the monetary value of unpaid health care was equivalent to $85.5 \%$ of the value of hospital services and that women contributed $72.2 \%$ of that monetary value through their work (ECLAC, 2017).

11. Faced with this new scenario, in which health systems are operating at maximum capacity, much of the health-care burden is being shifted to households. Without co-responsibility policies, this will undoubtedly increase care-related time pressures, particularly for women. High-risk groups, such as older people, will require support to perform more routine and basic tasks, such as buying food and medicine and making medical visits.

12. A study on this subject for Chile indicates that of the total population aged 65 or over living in a situation of dependency, $80 \%$ have a caregiver who lives in the same home, $34.2 \%$ have a care provider outside the home and are also cared for by a relative, $16.1 \%$ have care provided exclusively outside the home, and $4.5 \%$ do not receive any third-party care (ECLAC, 2019).

\footnotetext{
Economic Commission for Latin America and the Caribbean (ECLAC), CEPALSTAT [online] https://estadisticas. cepal.org/cepalstat/Portada.html, obtained on 20 March 2020.

Data obtained from time-use surveys in capital cities of the region

Data collected through the processing of household surveys for 16 countries (in or around 2017) available in the Household Survey Data Bank (BADEHOG) of ECLAC.
} 
13. A number of time-use surveys in Latin America provide insight into the care provided to older people within households. In Mexico, the national time-use survey provides data on the time spent on care for the population aged 60 or over and includes information on activities to support ICT use, transportation and company provided, even if the older person is not dependent or does not have a disability. In households with persons in this age range, women spend 18 hours per week on this type of care and men 15 hours. In Guatemala, data are collected on the total time spent caring for people aged 60 and over, but no specific activities are detailed; there, women spend 15 hours a week caring for older people and men 13 hours (ECLAC, 2018).

14. Women are particularly affected by the pressure on health systems because they account for $\mathbf{7 2 . 8 \%}$ of people employed in the sector in the region. ${ }^{5}$ The heightened pressure on health systems has resulted in extreme working conditions, such as long working hours, increasing the risk of health-care workers becoming infected with the virus. In order to overcome this crisis in a sustainable manner, decent working conditions must be ensured for women employed in the health sector as a matter of priority.

15. Women working in the health sector are still responsible for dependents or people in need of care within their households. They must continue to go to work in addition to this responsibility, which increases their excess workload and stress. This situation has come about in a regional context of persistent wage discrimination: the income of women working in the health sector is $25 \%$ lower than that of men in the same sector (ECLAC, 2019).

\section{The fragility of paid domestic work}

16. The care crisis, which has worsened in the current context, has a major impact on paid domestic work, a sector that employs $11.4 \%$ of working women in the region. According to estimates by the International Labour Organization (ILO), $77.5 \%$ of those engaged in paid domestic work are in the informal sector (ILO, 2016).

17. Paid domestic workers' vulnerability is a result of deregulation, the fact that they are less likely to be able to exercise their right to join a trade union or bargain collectively, and the low value afforded to their work by society in Latin America and the Caribbean.

18. This vulnerability is evident when, firstly, the increased demand for care falls on their shoulders in the face of school closures, greater demand for health care and the need to raise hygiene standards in the home, leaving them more exposed to the virus if there are infected people in the household where they work; secondly, when domestic workers cannot do their jobs because of social distancing recommendations or restrictions on movement and are uncertain whether their wages will be paid, especially those who do not have a formal contract; and thirdly, when demand for specific care during the pandemic requires domestic workers to perform tasks for which they are not necessarily prepared or trained, such as administering medicine or monitoring the health of the people they care for.

19. Furthermore, the lack of labour inspection in many countries leaves paid domestic workers exposed to demands from employers to continue working in the crisis situation. Experience in other regions of the world shows that, in quarantine situations, migrant domestic workers who live in their workplaces continue to carry out their activities without being paid, which not only leaves them without money, but also makes it impossible to send remittances to their countries of origin (Owen, 2020).

\footnotetext{
Data collected through the processing of household surveys for 16 countries (in or around 2017) available in the Household Survey Data Bank (BADEHOG) of ECLAC.
} 
The governments participating in the fourteenth session of the Regional Conference on Women in Latin America and the Caribbean adopted the Santiago Commitment, in which they agreed to:

Implement gender-sensitive countercyclical policies, in order to mitigate the impact of economic crises and recessions on women's lives and promote regulatory frameworks and policies to galvanize the economy in key sectors, including the care economy

Measure the multiplier effects of boosting the care economy in terms of women's labour market participation

_including work associated with the traditional knowledge, art and culture of indigenous, Afrodescendent, grassroots and rural women-, well-being, redistribution, economic growth and the macroeconomic impact of the care economy

Design comprehensive care systems from a gender, intersectional, intercultural and human rights perspective that foster co-responsibility between men and women, the State, the market, families and the community, and include joined-up policies on time, resources, benefits and universal, good-quality public services to meet the different care needs of the population, as part of social protection systems.

\section{The importance of gender-sensitive policies}

20. Today, as economies are battered by an unprecedented health crisis, the economic and social measures considered to alleviate the impacts of this situation must not involve tax cuts that could affect progress towards greater gender equality or curtail women's autonomy. In particular, it is important that women's time should not become, as has happened throughout history, an adjustment variable in States' efforts to address the crisis and the new economic scenarios.

21. The complexity of the problem calls for coordinated global and regional action, through collective efforts to address the crisis with resilience, while taking into account the diversity of women in the region and the differentiated impacts that this crisis will have on their lives. The policies and measures considered must take into account the possible consequences for migrant women, paid domestic workers, health workers, caregivers and informal workers, as well as those who work unpaid in the home.

22. The strategies adopted to address the crisis must be implemented by strengthening coordinated work with mechanisms for the advancement of women, and by involving women's and feminist organizations and movements, indigenous, Afrodescendent and rural women and grass-roots communities, so that they can contribute to the design of these strategies, adapting them to their realities (ECLAC, 2020).

23. In this crisis situation, when it is clear that the current system of economic organization shows is underpinned by care work - specifically, health care and the creation of conditions that protect people's lives - , this work that women do both inside and outside the home must be made visible and redistributed. As ECLAC has warned, one of the major challenges facing the region is the social reorganization of care so that responsibility is fully shared between the State, the market and families.

\section{Bibliography}

ECLAC (Economic Commission for Latin America and the Caribbean) (2020), Santiago Commitment (LC/CRM.14/XX), Santiago.

(2019), Women's autonomy in changing economic scenarios (LC/CRM.14/3), Santiago, December.

(2018), "Los cuidados en América Latina y el Caribe: textos seleccionados 2007-2018", Páginas Selectas de la CEPAL (LC/M.2018/4), December

__ (2017), Social Panorama of Latin America, 2016 (LC/PUB.2017/12-P), Santiago

ILO (Internacional Labour Organization) (2016), Policies to formalize paid domestic work in Latin America and the Caribbean, Lima, Programme for the Promotion of Formalization in Latin America and the Caribbean (FORLAC).

Owen, L. (2020), "Five ways the coronavirus is hitting women in Asia", BBC News, 8 March.

UNESCO (United Nations Educational, Scientific and Cultural Organization) (2020), "COVID-19 Educational Disruption and Response" [online] https://en.unesco. org/themes/education-emergencies/coronavirus-school-closures [date of reference: 30 March 2020].

This document is part of a series of reports prepared by the Economic Commission for Latin America and the Caribbean (ECLAC) on the evolution and effects of the COVID-19 pandemic in Latin America and the Caribbean. It was prepared by the Gender Affairs Division, directed by Mario Castillo, under the general coordination of Alicia Bárcena, Executive Secretary of ECLAC.

Copyright ๑ United Nations, 2020 